\title{
industrialização brasileira em perspectiva histórica
}

Wilson Suzigan

Instituto de Economia da UNICAMP

\section{Introdução}

Este trabalho, de natureza preliminar e exploratória, procura retomar a discussão de um temajá amplamente estudado - o desenvolvimento industrial brasileiro - com base num esquema analítico abrangente. Neste sentido, ele deve ser lido mais como um ensaio do que como um artigo formal e acabado. Por isso, algumas "liberdades" são tomadas, como, por exemplo, a menor preocupação com bases de dados ou de informações e a dispensa de citações no texto. Uma nota bibliográfica ao final do texto procura registrar as principais referências nas quais o trabalho se apoia.

Dada sua natureza, o presente trabalho tampouco pretende ser conclusivo. Talvez ajude mais a fazer perguntas e suscitar dúvidas do que a encontrar respostas e dirimir dúvidas. Se assim for, poderá ser encarado também como uma proposta de agenda de pesquisa que trate o tema de forma abrangente e na perspectiva histórica.

Seu principal objetivo é ressaltar a complexidade dos fatores que determinaram historicamente a industrialização do País, e mostrar a necessidade primordial de levar em conta esses fatores no debate atual sobre a necessidade, ou não, de uma política de desenvolvimento industrial. A partir daí é que se colocam questões específicas, tais como: qual seria uma política industrial factível num contexto de economia aberta e Estado mínimo? As empresas nacionais devem ser privilegiadas em relação ao capital estrangeiro? A indústria pode voltar a ser o "carrochefe" do crescimento e do emprego? Que desenvolvimento tecnológico seria necessário e qual a sua relação com o setor produtivo? Que inserção internacional seria mais desejável e qual o papel da indústria nesse âm- 
bito? A lista poderia ser ampliada, e talvez nem sejam essas as perguntas mais relevantes.

O princípio básico proposto é o de que há um conjunto amplo de fatores condicionantes do desenvolvimento industrial, constituindo um sistema complexo, articulado e bastante heterogêneo, que excede em muito os simples reducionismos baseados em preços relativos e dotação de fatores de produção, mas com a óbvia desvantagem de não ser modelável. Contudo, essa desvantagem precisa ser relativizada. A realidade ainda não está adequadamente representada nem mesmo nas ciências naturais.

Estes fatores condicionantes são apresentados na segunda seção adiante, e depois aplicados de forma genérica na interpretação de diferentes fases da industrialização brasileira na terceira seção. Antes, porém, resume-se com propósitos meramente expositivos as características gerais do desenvolvimento industrial do Brasil nas três grandes fases de sua evolução.

\section{As três grandes fases da evolução industrial do Brasil}

Entre o último quartel do século XIX e o final do século XX, a evolução da indústria no Brasil teve três grandes fases, cada uma com características distintas, embora matizadas em certos aspectos - especialmente na transição para as duas últimas fases. É claro que há uma miríade de fatores condicionantes nesse processo de evolução, cuja discussão será ensaiada na terceira seção adiante. Aqui, busca-se apenas caracterizar em linhas gerais as três fases em termos estritamente econômicos e no que se refere à orientação da política econômica. Para isso, destacam-se em cada fase: o desempenho da produção industrial, comparativamente aos do PIB e da produção agrícola; a natureza do desenvolvimento industrial (induzido ou auto-sustentado), o padrão de desenvolvimento alcançado (estruturalmente restrito ou crescentemente diversificado; tecnologicamente simples ou sofisticado), e a postura da política econômica tendo em vista o desenvolvimento industrial.

Primeiramente, em termos das taxas médias de crescimento de longo prazo, apesar das deficiências das estimativas para a primeira fase ${ }^{1}$, os

Como se sabe, não há estimativas adequadas para os agregados do PIB e da produção industrial para o período anterior a 1900, e, no caso da produção industrial, nem mesmo para os anos da primeira década do século, já que o único índice estimado para aqueles anos inclui apenas tecidos e produtos alimentares. 
dados da Tabela 1 permitem fazer uma clara distinção entre as três fases. Na primeira fase, a produção industrial teve um crescimento significativo, em parte explicado pela base ainda incipiente. A produção agropecuária comandava o crescimento do $\mathrm{PIB}^{2}$. Na segunda fase, o crescimento da produção industrial passou a liderar o crescimento do PIB, com uma taxa média anual equivalente a mais do que o dobro daquela da produção agrícola. E, na terceira fase, a produção industrial ficou praticamente estagnada, ou mesmo negativa, em termos per capita, enquanto que a agropecuária manteve um desempenho expressivo, voltando a liderar o crescimento do PIB. Entretanto, este cresceu a um ritmo medíocre, sobretudo quando descontado o crescimento demográfico.

Tabela 1. Brasil: taxas médias anuais de crescimento do PIB, da produção industrial e da produção agropecuária segundo grandes períodos, 1901-1998 (\%)

\begin{tabular}{cccc}
\hline Períodos & PIB & Indústria* & Agropecuária \\
\hline $1901-1929$ & 4,5 & $4,3^{* *}$ & 3,7 \\
$1933-1980$ & 6,7 & 8,7 & 3,8 \\
$1981-1999$ & 1,9 & 0,7 & 2,8 \\
\hline
\end{tabular}

\footnotetext{
* Até 1946, incluía somente a indústria de transformação; a partir de 1947 refere-se à indústria em geral (transformação mais extrativa mineral).

** Refere-se apenas a 1912-1929. O único índice disponível para os anos anteriores foi desconsiderado por sua escassa representatividade.

Fontes dos dados brutos: IBGE, Estatísticas Históricas do Brasil e Sistema de Contas Nacionais.
}

Como se caracterizou em linhas gerais cada uma dessas fases? A primeira foi uma fase de desenvolvimento industrial dependente da agricultura de exportação, que induzia o crescimento da produção industrial à medida que criava mercado, gerava capacidade de importar e estimulava a formação de capital. Seu padrão de desenvolvimento era estruturalmente restrito, centrado nas indústrias tradicionais produtoras de bens de consumo e alguns insumos menos sofisticados, emborajá estivesse ocorrendo uma pequena diversificação em direção aos insumos pesados. A política econômica, embora suscetível aos pleitos protecionistas da classe industrial emergente, era inteiramente dominada pelos interesses da agricultura, os quais detinham a hegemonia política na época.

Para percebê-lo, basta aplicar ponderações às taxas de crescimento setoriais. Do total do valor adicionado pela agricultura e pela indústria em 1919 (conforme o Censo de 1920), a agropecuária respondia por cerca de quatro quintos. 
$\mathrm{Na}$ segunda fase, mudou a natureza do desenvolvimento industrial. O crescimento da produção industrial adquiriu dinamismo próprio, impulsionado primeiro pela substituição de importações (SI) e depois, cada vez mais intensamente, pela expansão do mercado interno (consumo mais investimento) e,por fim, pelas exportações de produtos manufaturados sob forte esquema de promoção, inclusive com subsídios. O padrão de desenvolvimento industrial avançou substancialmente em termos estruturais, convergindo para o padrão estrutural e tecnológico das economias industrializadas, embora sem alcançá-lo inteiramente. Por sua vez, a orientação da política econômica tornou-se francamente industrializante, apesar da assistência à agricultura (em crise nos anos trinta) e da persistência de políticas agrícolas com alguns subsídios. Estes, no entanto, em alguns períodos, apenas compensaram outras formas de extração de renda da agricultura em beneficio da indústria e das atividades urbanas em geral.

Finalmente, na terceira fase, o dinamismo da produção industrial foi enfraquecido por causas estruturais (fim da SI em escala significativa) e por problemas conjunturais (crise macroeconômica). O padrão de desenvolvimento industrial regrediu, e a política econômica centrou-se na estabilização macroeconômica e em mudanças institucionais lato sensu (liberalização comercial, abertura da economia ao capital estrangeiro, privatizações), abandonando-se qualquer orientação política de longo prazo, especialmente quanto ao desenvolvimento industrial.

Esse panorama geral da evolução da indústria no Brasil serve apenas para estabelecer os fatos, de resto já bastante conhecidos. A questão fundamental é como explicar essas diferentes fases e, sobretudo, as suas inflexões. É o que se procura fazer, de um modo exploratório e bastante preliminar, nas seções seguintes.

\section{Fatores condicionantes do desenvolvimento industrial}

É razoável admitir que nenhum país pode se tornar industrializado a partir do nada. Sempre há um conjunto de fatores condicionantes que abrangem desde o espaço geográfico até aspectos culturais, passando por fatores políticos, econômicos e de política econômica, sociais, institucionais, científicos e tecnológicos, e pela forma de inserção na economia mundial. Em conjunto, esses fatores condicionam o processo de industrialização, ampliando ou limitando as possibilidades de expansão e de aprofundamento desse processo. Certamente, não há qualquer novidade em cada um destes fatores isoladamente, os quais, em sua maioria 
já foram analisados por historiadores econômicos, sociólogos, cientistas políticos e outros pesquisadores. O que, sim, poderia representar alguma "novidade" seria o tratamento conjunto desses fatores (ou tomandose cada um individualmente, como parte do conjunto com o qual se inter-relaciona), aplicado ao estudo da industrialização brasileira.

Sem pretender ser exaustivo, e correndo vários riscos (superficialidade, erros de classificação, omissões importantes), proponho que sejam considerados relevantes os seguintes fatores:

1. Geografia econômica (tamanho do país,base de recursos naturais, distribuição da produção no espaço geográfico) e população (tamanho, distribuição etc).

2. Políticos, abrangendo desde a natureza do regime vigente até a existência de "determinação política" (political will), tendo em vista o desenvolvimento industrial, passando por questões como federalismo, regionalismo, ação de grupos de interesse organizados, sindicalismo e outros.

3. Institucionais: organização do Estado, da economia e da sociedade; leis e regulamentações que regem os mercados (concorrência), as relações de trabalho e o suprimento de bens e serviços públicos.

4. Econômicos: estrutura produtiva prevalecente, estrutura de poder econômico (grupos nacionais, Estado, capital estrangeiro), sistema financeiro, infra-estrutura.

5. Pensamento econômico dominante: liberalismo, nacional-desenvolvimentismo, socialismo, neoliberalismo.

6. Sistema de desenvolvimento científico e tecnológico: ensino e pesquisa de pós-graduação, centros de $\mathrm{P} \& \mathrm{D}$, institutos de pesquisa, laboratórios de certificação, regulamentação de normas técnicas, padrões de qualidade, articulação do sistema de C\&T com o setor produtivo.

7. Relações internacionais: inserção comercial, financeira e nos fluxos de investimento direto de capital estrangeiro, acordos de comércio ou de integração econômica (regionais, hemisféricos, internacionais), mecanismos de transferência de tecnologias, normas e regulamentações internacionais específicas (setoriais, ambientais, patentárias e outras).

8. Sociais: demografia (crescimento, imigração, migrações internas), emprego e relações de trabalho, distribuição da renda, pobreza, previdência, saúde, educação e formação de recursos humanos qualificados.

9. Culturais: patrimonialismo,burocracia estamental, elites rentistas, fraco espírito empreendedor, captura do Estado por interesses privados, ausência de confiança (trust), fraco associativismo/cooperativismo, ausência de solidariedade social. 
É evidente que esta lista já embute juízos de valor e informações específicas. Sua aplicação requereria um amplo conhecimento interdisciplinar, bem como um esforço de resenha da literatura e, possivelmente, a realização de novas pesquisas que, evidentemente, estão fora do alcance e das cogitações deste trabalho. O que aqui se pretende, nunca é demais repetir, é apenas aplicar genericamente esse esquema num esboço de interpretação das três fases do desenvolvimento industrial do Brasil, talvez levantando questões e suscitando dúvidas, mais do que propor novos insights. De qualquer modo, se essas questões e dúvidas forem pertinentes, elas poderão vir a nortear um esforço de pesquisa (certamente coletivo), visando uma interpretação em perspectiva histórica do desenvolvimento industrial brasileiro segundo esse conjunto de fatores condicionantes. No mínimo, isto permitiria ter muito maior clareza sobre os obstáculos e as possibilidades para que o País volte a ter uma política de desenvolvimento industrial.

\section{Esboço de interpretação das três grandes fases do desenvolvimento industrial segundo o esquema proposto}

É evidente, em primeiro lugar, que alguns fatores (ou partes deles) são dados, enquanto outros precisam ser construídos. Por exemplo, quanto à geografia econômica, é claro que o tamanho do país é um dado, e condiciona a industrialização. Por si só implica maior ou menor grau de desenvolvimento industrial. Países grandes tendem a desenvolver desde logo algumas atividades industriais substitutivas de importações e a aprofundar mais a SI do que países pequenos em virtude do seu grande mercado interno e da proteção natural dada por custos de transportes e outras dificuldades de importação. Portanto, não há dúvida que, por esse aspecto, o Brasil teve sempre uma "vocação natural" para o desenvolvimento industrial em algum grau.

Da mesma forma, a base de recursos naturais é também dada e sua exploração implica alguma forma de distribuição da atividade econômica no espaço geográfico, o que naturalmente gera processos de causação cumulativa que induzem graus variados de industrialização regional, com maior ou menor sucesso. O caso do café já foi exaustivamente estudado e é, sem dúvida, o mais bem sucedido. Mas será que outros casos (inclusive menos bem-sucedidos) não seriam historicamente relevantes, e porisso merecedores de estudos mais aprofundados? Exemplos: algodão/indústria têxtil algodoeira no Nordeste, pecuária/carnes industrializadas e produtos de couro no Sul, minérios/indústria meta- 
lúrgica no Sudeste, e assim por diante, incluindo as fases mais recentes do desenvolvimento.

Também são dados, por difíceis de mudar, os fatores culturais. É possível que características e heranças culturais tenham responsabilidade em muitos dos problemas que historicamente acompanharam o desenvolvimento industrial e, de certa forma, o restringiram, como por exemplo a elevada concentração de renda e de poder, o atraso educacional, a pobreza endêmica, a rigidez da extratificação social, o individualismo excessivo e sua contrapartida - a resistência atávica a qualquer forma de cooperativismo, o desinteresse pela construção da nação, a desconfiança como princípio nas relações pessoais e entre agentes econômicos, e possivelmente outros.

Dados esses condicionantes de natureza permanente, ou que dificilmente podem ser mudados, as três grandes fases da industrialização podem ser interpretadas em linhas gerais com base no conjunto dos demais fatores que compõem o esquema proposto. O ponto de partida, portanto, é positivo por um lado - o tamanho do país e sua base de recursos naturais - e negativo por outro - uma herança cultural desfavorável do ponto de vista de alguns atributos necessários ao desenvolvimento industrial. Reafirmo que a preocupação do texto não é produzir uma análise abrangente, com remissões à literatura e fundamentada por pesquisas próprias. Ao contrário, busca-se apenas apontar tendências gerais e, quem sabe, suscitar um novo interesse pelo tema, sempre que possível e pertinente, levantando dúvidas, questões e pontos que motivem novas pesquisas.

O crescimento industrial induzido pela economia agro-exportadora, 1901-1929

O crescimento industrial induzido pela economia de base agro-exportadora já foi bastante estudado, em particular no que respeita ao café como principal produto de exportação. Entretanto, cabe ainda perguntar: que indústrias foram induzidas nesse período, por estarem diretamente atreladas às atividades agro-exportadoras? Que outras foram indiretamente induzidas pelo efeito-renda? Qual foi a importância relativa dessas indústrias? A partir de que momento a demanda por bens industrializados passou a ser, em parte, gerada pela própria indústria (insumos, bens intermediários e máquinas), e qual a importância quantitativa dessa demanda? Em termos regionais, que outros casos de industrialização induzida por atividades agropecuárias de exportação foram relevantes? E, de um modo geral, como explicar o início da diversificação da pro- 
dução industrial entre a Primeira Guerra Mundial e o final dos anos vinte, fugindo dos padrões "estabelecidos"para um crescimento industrial induzido? E por que essa diversificação não avançou mais substancialmente? Em suma, seria interessante ampliar o objeto de estudo, focalizando diversos processos localizados de crescimento industrial (muito já foi feito nesse campo; é claro que uma resenha abrangente seria a primeira tarefa), abrindo o leque dos fatores condicionantes inter-relacionados a serem estudados.

Até que ponto houve uma "construção" deliberada desses fatores naquela fase? Certamente não houve. O regime político, na transição do Império para a República Federativa, continuou sendo dominado pelos interesses das oligarquias agrárias. Não havia espaço no projeto político para uma construção deliberada de fatores industrializantes.

A conjugação de interesses políticos agrário-exportadores com: (1) um arranjo institucional voltado para a defesa desses interesses; (2) uma estrutura produtiva montada para atender as necessidades da referida economia (transportes,bancos,mão-de-obra escrava ou de imigrantes), em que a própria elite agrária investia,junto com o Estado e o capital estrangeiro, atraído por garantia de juros, auto-reforçando o esquema de poder; e (3) o pensamento econômico liberal, determinavam a orientação fundamental da política econômica, que, obviamente, pautavase pelos interesses dominantes.

Apesar disso, algumas brechas nessa pauta foram criadas por grupos de interesse organizados no seio da indústria nascente (Associação Industrial, criada em 1881; sindicatos de trabalhadores de algumas indústrias; o Centro Industrial do Brasil) para pleitear proteção e estímulos à indústria manufatureira.Até algumas políticas destinadas a atender interesses agrários acabaram favorecendo a indústria - como, por exemplo, a imigração, que acabou sendo importante fonte de mão-de-obra industrial. O mesmo se daria com o capital estrangeiro investido em ferrovias e energia, mas que acabou tendo efeitos positivos sobre a industrialização - o primeiro pelas atividades industriais de construção de material ferroviário em oficinas próprias, e o segundo pelas economias externas geradas ao substituir a energia a vapor por energia elétrica, facilitando a transição da indústria ao paradigma energético já alcançado nos países líderes do crescimento industrial no início do século XX.

Os efeitos regionais dessa transição ainda não foram suficientemente estudados no Brasil. As primeiras usinas hidrelétricas foram constuídas nos Estados de São 
Entretanto, o País não alterou sua forma de inserção no comércio internacional, consolidando, pelo contrário, sua posição de supridor mundial de commodities agrícolas e agro-industriais, com alguma diversificação nos anos vinte, e manteve-se praticamente à margem do avanço tecnológico-produtivo da segunda revolução industrial.

\section{A industrialização acelerada, 1933-1980}

Com a ruptura provocada pela crise do início da década de 1930, iniciou-se um período em que, não obstante as alternâncias políticas e de política econômica, a industrialização do País avançou em ritmo acelerado. A dinâmica da produção industrial tornou-se autônoma, "descolando-se" da dinâmica da produção agropecuária. A taxa média de crescimento da produção industrial entre 1933 e 1980 (8,7\% ao ano) fez dobrar o volume da produção a cada oito anos e quatro meses! Isto resultou de um longo processo, marcado por avanços e recuos ${ }^{4}$, de construção deliberada de consenso político, arranjos institucionais, estrutura econômica, relações internacionais e relações sociais próindustrialização.

Como se tornou viável esse processo? Primordialmente pela mudança do regime político, e, a partir dela, por mudanças na orientação da política econômica,desencadeando novos arranjos institucionais, mudanças na estrutura produtiva, desenvolvimento da infra-estrutura e do sistema de desenvolvimento científico e tecnológico, e um novo padrão de relações internacionais.

A base de poder da oligarquia rural havia sido minada pela crise do café. A Grande Depressão precipitou a crise econômica, e a Revolução de 1930 pôs fim à hegemonia política da oligarquia. Daí por diante, a política econômica, apesar do socorro à agricultura nos anos trinta, passou a ser influenciada por um leque mais amplo de interesses. A industrialização entrou definitivamente na agenda política e da política

Paulo e do Rio de Janeiro no início do século XX. A indústria nesses Estados iniciou a transição para a eletricidade bem antes que a dos Estados do Nordeste, por exemplo. Por causa disso, na época da Primeira Guerra, quando o carvão-vapor importado ficou extremamente caro e escasso, a indústria do Nordeste provavelmente ficou em forte desvantagem competitiva,perdendo participação no produto industrial a favor da indústria do Sudeste.

Esses avanços e recuos ainda merecem estudos mais aprofundados, nos termos aqui propostos. 
econômica. Entretanto, foi somente nos anos cinqüenta e durante o regime militar que se chegou a executar uma deliberada política de desenvolvimento industrial (no sentido de concertação entre Estado e agentes privados, e de coordenação de instrumentos de política), no âmbito dos planos de desenvolvimento econômico. Forças políticas setoriais e regionais organizaram-se para pleitear políticas específicas, que se consubstanciaram em grandes transferências de recursos (via proteção e subsídios fiscais/creditícios) da sociedade para o capital industrial. O sindicalismo, por seu lado, após fortalecer-se entre os anos trinta e cinqüenta, foi sufocado pelo regime militar. Com isso, o crescimento acelerado da produção não se traduziu em ganhos substanciais de salário real, o que agravou a tendência à concentração de renda, limitou o tamanho do mercado interno e direcionou a estrutura produtiva da indústria para bens de luxo.

A mudança na orientação da política econômica refletiu as guinadas políticas. Prevaleceram o nacional-desenvolvimentismo e o intervencionismo estatal, que amalgamavam forças políticas e objetivos econômicos consubstanciados no projeto industrializante. Mesmo quando o pensamento econômico liberal se impôs, durante curtos períodos, não lograva alterar substancialmente essa orientação.

Houve, com isso, uma contínua construção institucional ao longo de todo o período. O Estado aparelhou-se em termos organizacionais para a coordenação econômica (planos, programas de desenvolvimento industrial e tecnológico, instituições de fomento, financiamento e regulação); criaram-se normas, legislações e regulamentações econômicas; foram institucionalizadas políticas setoriais, regionais, de comércio exterior e outras; e passou-se a exercer forte regulação em algumas atividades (investimentos setoriais, investimentos de capital estrangeiro) assim como nas relações de trabalho, em mercados concentrados, nos preços e salários, nas tarifas públicas e no acesso a tecnologias. Apesar de seus resultados positivos em termos de desenvolvimento industrial, esse arranjo institucional (decisão e coordenação centralizadas) tinha como contrapartida uma limitação do espaço de atuação das forças de mercado, o que também limitaria a busca pelos agentes econômicos de maior eficiência no uso dos fatores produtivos.

Mesmo assim, a estrutura da produção industrial diversificou-se, em convergência com os padrões das economias mais industrializadas, inclusive do ponto de vista tecnológico (nos processos produtivos, mais do que nos produtos). A par da forte participação direta do Estado na indústria, fortaleceram-se grupos econômicos nacionais e cresceu 
substancialmente a participação do capital estrangeiro por investimento direto. Complementarmente, o Estado investiu pesadamente na infraestrutura, garantindo o suprimento de energia e de serviços de comunicações, e promovendo a expansão da malha de transportes, sobretudo os rodoviários. Agentes financeiros públicos fomentaram o desenvolvimento industrial e tecnológico, e a poupança privada, intermediada pelo sistema financeiro, custeou a construção civil, sob um padrão de financiamento que "sacava contra o futuro", gerando endividamento externo, déficits públicos, e fundos específicos atuarialmente irrecuperáveis.

A constituição de um sistema nacional de desenvolvimento científico e tecnológico também foi iniciada nesse período, abrangendo instituições públicas de apoio à pesquisa e à pós-graduação, centros de P\&D nas empresas estatais, institutos públicos de pesquisas, laboratórios de certificação de qualidade, e regulamentação de normas técnicas e padrões industriais. Mas, não se logrou articular esse sistema com o sistema produtivo.

Um novo padrão de inserção internacional começou a ser moldado. O Brasil foi gradativamente deixando de ser um mero supridor de commodities agropecuárias e absorvedor de capitais de empréstimo, tornando-se crescentemente um exportador de produtos manufaturados e um recebedor de investimentos diretos de capital estrangeiro, embora ainda continuasse a ser um importante tomador de recursos no mercado financeiro internacional, especialmente durante os anos setenta. Além disso, a agenda de relações internacionais tornou-se ampla, incluindo acordos com parceiros comerciais, acordos comerciais multilaterais, negociações com agências internacionais de crédito, e acordos de integração econômica regional. A expansão da economia mundial, principalmente a partir do pós-Guerra, favoreceu essa mudança no padrão de inserção internacional.

Mudanças do ponto de vista social também foram significativas nesse período, em sentido negativo mais do que positivo. A crescente urbanização associada à industrialização, bem como a modernização da agricultura, provocaram intensos movimentos migratórios, que levaram a um rápido adensamento populacional das áreas metropolitanas, gerando um excedente de mão-de-obra urbana mal qualificada, que não conseguiria ser absorvida pela indústria apesar do crescimento acelerado da produção. Isso ajudou a pressionar para baixo os salários reais. Foram feitos significativos investimentos em educação e saúde, mas insuficientes e inadequados para as necessidades do setor produtivo, mormente na etapa mais avançada da industrialização, ao final dos anos setenta. 
Por que a indústria perdeu completamente o dinamismo a partir dos anos oitenta? Por que, apesar de alguns curtos períodos de retomada do crescimento da produção, o desenvolvimento industrial não mais avanç o u, e, até pelo contrário, regrediu? É claro que houve causas econômicas, tanto estruturais (por exemplo, a perda de dinamismo da substituição de importações) quanto conjunturais (instabilidade macroeconômica subsequente à crise da dívida). Mas, houve também, e principalmente, razões de ordem política.

Já no início do último governo da ditadura, ficara claro que o nacionaldesenvolvimentismo e o intervencionismo estatal haviam perdido espaço. Deixou de existir um "projeto nacional" de industrializaçãos. A crise do início dos anos oitenta sobrepôs objetivos de estabilização macroeconômica aos objetivos de desenvolvimento industrial, ou econômico de modo geral. Todas as formas anteriormente construídas de coordenação (planos, programas setoriais de investimento e desenvolvimento tecnológico) foram sendo descartadas. Mas, o mercado não pôde atuar como mecanismo de coordenação descentralizada, uma vez que a política econômica manteve a economia do País rigorosamente fechada ao comércio internacional, ampliando os subsídios à exportação e impondo severas formas de controle e regulação aos preços, salários e tarifas públicas, além de restrições ao nível de atividades da economia.

Daí por diante, prevaleceu a instabilidade macroeconômica. Políticas industriais chegaram a ser anunciadas, e até regulamentadas. Entretanto, muito pouco foi de fato implementado. A razão principal foi a falta de decisão política no sentido de dar continuidade ao desenvolvimento industrial. E, a partir do fator político, todos os demais fatores condicionantes do desenvolvimento industrial foram sendo gradualmente "desconstruídos", mesmo após a conquista da estabilização monetária (mas não da estabilidade macroeconômica) nos anos noventa.

No quadro político, com a crise fiscal-financeira do Estado, este, que já nada coordenava, foi aos poucos saindo de cena. Além das privatizações, o Governo cortou recursos orçamentários destinados ao financiamento industrial e ao desenvolvimento tecnológico, e reduziu drasticamente a

Uma evidência, até curiosa, é o fato de que, apesar de ter sido elaborado um III PND (Plano Nacional de Desenvolvimento) no início do governo Figueiredo, esse plano nunca mais foi sequer mencionado, e a sua própria existência até continua sendo ignorada por muitos. 
concessão de incentivos e subsídios fiscais/financeiros a investimentos, P\&D, exportação e outros. A instabilidade levou muitas empresas a optarem pelo mercado financeiro como locus de acumulação, em substituição ao respectivo setor produtivo, e as lideranças empresariais se acomodaram à nova situação.

Posteriormente, a abertura da economia do País ao capital estrangeiro, juntamente com a abertura do mercado interno ao comércio internacional, mudou radicalmente o ambiente econômico e levou a processos de desnacionalização, conflitos entre o Estado e as associações empresariais, a fortes lobbies setoriais por políticas protecionistas (em vários casos atendidos, em desacordo com a própria orientação neoliberal, e sem qualquer referência a objetivos mais amplos de desenvolvimento industrial), e à crise do federalismo, à medida que diversos governos estaduais, na ausência de diretrizes nacionais, buscaram atrair investimentos produtivos promovendo um verdadeiro leilão de subsídios (guerra fiscal). Por último, o sindicalismo, após renascer nos anos oitenta, voltou a ser enfraquecido na década de 1990 pelo desemprego causado pela recessão, e por reestruturações técnico-produtivas das empresas.

Desorganizaram-se e enfraqueceram-se também,pela perda de poder político e de funções, tanto a organização institucional do Estado como as estruturas institucionais da economia e da sociedade. Montadas segundo os parâmetros de um processo histórico de desenvolvimento industrial e tecnológico comandado pelo Estado, ambas se revelaram pouco funcionais quando esse processo passou a ser comandado pelo mercado nos anos noventa. Os padrões de relações entre agentes econômicos (Governo-empresas, empresas-instituições de pesquisa, sistema financeiro-indústria,capital-trabalho), bem como as estruturas de mercado e os padrões de concorrência nunca se ajustam de imediato. Porisso, as políticas de liberalização comercial, privatização, desregulação e outras, no âmbito de políticas industriais, tecnológicas e de comércio exterior, não produziram (ou demoraram muito a produzir) os efeitos esperados. A hipótese de histerese institucional já foi sugerida, mas ainda está para ser testada empiricamente.

Em conseqüência, a estrutura produtiva regrediu (ou, segundo alguns autores, "desinchou", voltando ao normal). Não só a participação da indústria de transformação no PIB perdeu alguns pontos percentuais, como também cadeias produtivas inteiras foram desarticuladas, e segmentos de indústrias de alta tecnologia, que estavam em implantação, foram desativados, levando a uma estrutura produtiva com "especialização regressiva". Uma nova estrutura de poder foi gestada, com Estado mínimo 
(regulador), capital estrangeiro dominante em grande número de setores, e grupos privados nacionais reestruturados mas com limitada capacidade financeira, e sem sinergias produtivas. Além disso, os serviços de infraestrutura sofreram longo processo de deterioração, com cortes de investimentos, políticas tarifárias predatórias e, por último, privatizações que não foram precedidas da necessária regulamentação das respectivas agências reguladoras. O resultado foi a geração de deseconomias externas para as empresas usuárias dos serviços de infra-estrutura.

$\mathrm{Na}$ mesma linha, o sistema financeiro também deixou de ser funcional para o desenvolvimento industrial.As agências públicas de financiamento sofreram severos cortes orçamentários nos anos oitenta e início dos noventa, depois "especializaram-se" como agências de privatização e "hospitais de empresas". Só muito recentemente voltaram a desempenhar papel relevante na reestruturação de alguns setores industriais e no financiamento de exportações. Os agentes financeiros privados, bem como o mercado de capitais, mantiveram sua posição de menor relevância na mobilização de recursos para o desenvolvimento industrial.

A instabilidade macroeconômica afetou também o sistema de desenvolvimento científico e tecnológico, que sofreu corte de recursos orçamentários, redução ou fechamento de centros de P\&D (principalmente nas empresas estatais), perda de pessoal técnico, redução dos orçamentos de fundos específicos de financiamento a projetos de desenvolvimento científico e tecnológico, e cortes de bolsas de pesquisa e de pós-graduação.A questão que se coloca é a de que desenvolvimento industrial será doravante possível com o que resta do sistema de desenvolvimento científico e tecnológico?

Relacionado a tudo isso, o padrão de inserção do País no comércio internacional, que havia avançado até 1985, ampliando a participação de produtos manufaturados na pauta de exportação para cerca de $55 \%$, deixou de progredir daí por diante. Na verdade, até regrediu se considerarmos que aproximadamente $60 \%$ da pauta de exportação são constituídos atualmente por produtos básicos, semi-manufaturados e commodities industriais (aço, suco de laranja, celulose, açúcar, borracha, produtos de madeira, carnes industrializadas, café solúvel).

Os vínculos comerciais enfrentaram vários contenciosos com parceiros - por exemplo, nos campos da informática e das patentes farmacêuticas. Acordos regionais de integração econômica (Mercosul) e multilaterais de comércio (OMC) passaram a restringir o raio de manobra da política de comércio exterior.Tornou-se crucial a capacitação técnica em defesa comercial e em negociações internacionais. Crescentes fluxos 
de investimento direto estrangeiro passaram a ser dirigidos ao Brasil, atraídos pela abertura da economia, pelas privatizações e pelo processo de fusões/aquisições de empresas, implicando crescentes remessas de rendimentos ao exterior. Os fluxos de capital financeiro também se intensificaram, particularmente nos anos noventa, beneficiando-se do diferencial juros/câmbio, com a contrapartida de maiores riscos para o País em termos de instabilidade e ameaças de ataques especulativos.

Por fim, a perda de dinamismo econômico e os efeitos das políticas de ajuste macroeconômico geraram um agravamento da questão social: desemprego crescente, aumento da pobreza (atenuado em alguns dos anos mais recentes pela estabilização monetária), piora na distribuição de renda, crise previdenciária, crise do sistema de saúde, e pouco avanço no sistema educacional, sobretudo em relação ao que seria desejável numa sociedade democrática na era da informação e da comunicação.

\section{Algumas conclusões}

O propósito destas notas foi o de retomar o debate sobre a industrialização brasileira numa perspectiva histórica de longo prazo, e com base num esquema de análise bastante abrangente e interdisciplinar. Como foi enfatizado na introdução, a idéia era simplesmente despertar novos interesses de pesquisas, levantar dúvidas mais do que encontrar respostas, e, sobretudo, mostrar a complexidade dos fatores que determinam o desenvolvimento industrial e, em decorrência, a necessidade da adoção de uma política de desenvolvimento industrial para que a indústria possa recuperar seu dinamismo.

Quanto a novos interesses de pesquisa, várias sugestões foram feitas ao longo do texto, mas sem preocupação de sistematizar. Talvez um primeiro passo seja organizar uma agenda de pesquisas com a abrangência sugerida no texto e em perspectiva histórica. Sem pretender ser exaustivo, essa agenda poderia conter: estudos de períodos específicos, em particular daquele que cobre a transição da segunda para a terceira fase da industrialização, marcando o fim do dinamismo da indústria de transformação; uma avaliação, inclusive em termos empíricos, da relação entre instituições e desenvolvimento industrial; estudos sobre as inter-relações da geografia econômica com o desenvolvimento industrial evidenciando, por um lado, processos localizados de causação cumulativa que historicamente deram origem a industrializações regionalmente circunscritas e, por outro, as tendências recentes de formação de aglomerações 
industriais - concentrações geográficas e setoriais de empresas interrelacionadas; análises de economia política da política industrial, destacando a atuação de grupos de interesse e a influência da corrente hegemônica de pensamento econômico; estudos da adequação do sistema de $\mathrm{C} \& \mathrm{~T}$ ao desenvolvimento de uma indústria com capacidade de inovação, enfatizando sobretudo as relações entre o sistema de C \& T e as empresas industriais; mensuração das deficiências da infra-estrutura econômica como geradoras de deseconomias externas para as empresas industriais; avaliação dos impactos e das restrições, do ponto de vista da política industrial, decorrentes dos acordos internacionais de comércio e de integração econômica; verificação da hipótese de tendência à especialização regressiva da indústria de transformação a partir da abertura ao comércio internacional nos anos noventa e, se confirmada, dos meios para reverter essa tendência; estudo dos ingressos de investimento direto estrangeiro na indústria e da possível desnacionalização de segmentos industriais; avaliação das possibilidades da indústria voltar a liderar o crescimento da economia e gerar empregos, diretos e indiretos, e outros temas específicos a setores, regiões ou instrumentos de política industrial.

Não se pretende apresentar aqui uma recomendação de política. Entretanto, deve ficar claro desde logo que a necessária política de desenvolvimento industrial não pode simplesmente replicar as antigas práticas de proteção setorial indiscriminada e subsídios fiscais e financeiros. No atual contexto, há limitações impostas por restrições internas (institucionais, políticas e de política econômica), bem como por regulamentações e acordos internacionais. Porisso, uma tarefa prévia seria a de avaliar os limites e as possibilidades de uma tal política. Mas, a própria retomada do debate sobre o desenvolvimento industrial, e sobre a oportunidade de uma política nesse sentido, já seria um enorme avanço em relação ao status quo atual, em que prevalece uma postura hands-off no que diz respeito ao papel das políticas públicas em relação ao desenvolvimento industrial. Essa postura voluntarista tem tido custos elevados em vários sentidos: baixo crescimento, perda de empregos, estagnação da renda per capita, atraso tecnológico, inserção internacional regressiva em produtos pouco dinâmicos no comércio mundial, além das seqüelas sociais decorrentes. A implementação de uma política de desenvolvimento industrial nos dias de hoje constitui um desafio política e tecnicamente muito mais difícil de enfrentar do que foi no passado. Mas, o ganho potencial obtido a partir dela é enorme. 
Por sua natureza, este trabalho apoia-se - implícita ou explicitamente - em ampla bibliografia. Boa parte desta é constituída pelas obras de referência para, como se diz,"entender o Brasil". Destaco, entre tantas, e sem preocupação quanto a ordem, as seguintes: Os Sertões, de Euclides da Cunha; Retrato do Brasil, de Paulo Prado; Casa-Grande e Senzala, de Gilberto Freyre; Raízes do Brasil, de Sérgio Buarque de Holanda; Formação do Brasil Contemporâneo, de Caio Prado Júnior; Coronelismo, Enxada e Voto, de Vítor Nunes Leal; Instituições Políticas Brasileiras, de Oliveira Viana, Formação Econômica do Brasil, de Celso Furtado, e Os Donos do Poder, de Raimundo Faoro. Uma coletânea recém editada, contendo resenhas comentadas dessas e de outras obras de referência, pode ser útil ao leitor, tanto para um primeiro contato com essa literatura quanto para um releitura rápida.Trata-se de Introdução ao Brasil: um Banquete no Trópico. São Paulo: Ed. SENAC, 1999. E, como referência mais geral e abrangente, a monumental História Geral de Civilização Brasileira, sob a direção de Boris Fausto (período republicano) e de Sérgio Buarque de Hollanda, com assitência de Pedro Moacyr Campos (períodos monárquico e colonial).

Especificamente sobre os fatores condicionantes do desenvolvimento industrial, a presente elaboração baseou-se na observação empírica e, sobretudo, nas obras de referência. Mas, um importante artigo serviu de "inspiração" metodológica: Helen Shapiro \& Lance Taylor, The State and Industrial Strategy. World Development, 18 (6), 1990, p. 861-878.

Sobre a evolução da indústria no Brasil existe, sabidamente, uma enorme bibliografia abrangendo aspectos políticos,institucionais, econômicos, de política econômica, tecnológicos, regionais, de financiamento e de relações internacionais. Não há espaço aqui para listar toda essa bibliografia. Limito-me a mencionar três obras que de modo geral dialogaram com essa bibliografia, realizaram pesquisas adicionais em fontes primárias de dados e informações e quantificaram o crescimento da produção e do investimento na indústria: meu próprio livro (com perdão pela auto-citação) Indústria Brasileira: Origem e Desenvolvimento, São Paulo: Hucitec (nova edição, no prelo; anteriormente publicado pela Editora Brasiliense, 1986); Pedro S. Malan, Regis Bonelli, Marcelo de P. Abreu e José Eduardo de Carvalho Pereira, Política Econômica Externa e Industrialização no Brasil, 1939/52, Rio de Janeiro: IPEA/INPES, 1977; e Regis Bonelli, Ensaios sobre Política Econômica e Industrialização no Brasil. Rio de Janeiro: SENAI/CIET, 1995. 
Outros trabalhos têm abordado também, mais recentemente, aspectos específicos da evolução da indústria no Brasil. Sem qualquer pretensão de abrangência e muito menos de oferecer uma resenha temática, destaco os que seguem.

Avaliações de âmbito mais geral da estrutura e da competitividade da indústria encontram-se em: Estudo da Competitividade da Indústria Brasileira, coordenado por Luciano G. Coutinho e João Carlos Ferraz. Campinas: Papirus/UNICAMP, 1994; Made in Brazil. Desafios Competitivos da Indústria Brasileira, de João Carlos Ferraz, David Kupfer e Lia Haguenauer. Rio de Janeiro: Campus, 1995, e Em Busca do Futuro: Competitividade no Brasil, organizado por Carlos Anibal Nogueira da Costa e Carlos Alberto Arruda. Rio de Janeiro: Campus, 1999. Na mesma linha, porém mais focalizado, está o trabalho de Mário L. Possas, Competitividade: fatores sistêmicos e política industrial. Implicações para o Brasil, in Antonio Barros de Castro e Adriano Proença (Orgs.), Estratégias Empresariais na Indústria Brasileira: discutindo mudanças. R io de Janeiro: Forense Universitária, 1996. Todos esses trabalhos discutem também as políticas industrial e tecnológica, mas estas últimas são mais detalhadamente discutidas em: Fábio S. Erber e José E. Cassiolato, Política industrial: teoria e prática no Brasil e na OCDE. Revista de Economia Política, 17 (2), abril-junho de 1997,p.32-43, e W. Suzigan e Annibal V. Villela, Industrial Policy in Brasil. Campinas: Ed. IE/UNICAMP-FAPESP, 1997.

Quanto aos impactos da abertura comercial sobre a indústria, a referência mais importante é o trabalho de Maurício Mesquita Moreira, A indústria brasileira nos anos 90 . O quejá se pode dizer? In: F. Giambiagi e M. M. Moreira (Orgs.) A Economia Brasileira nos Anos 90. Rio de Janei-ro: BNDES, 1999. Mudanças na estrutura produtiva e no padrão de desenvolvimento industrial são avaliadas por Regis Bonelli e Robson R. Gonçalves, Padrões de desenvolvimento industrial no Brasil: passado e futuro, in CNI, O Futuro da Indústria no Brasil e no Mundo. Rio de Janeiro: Campus, 1999 (cap.6) e, nesse mesmo livro, por Antonio Barros de Castro, Esgotamento versus continuidade na indústria brasileira (cap.7). No âmbito dessas mudanças, aspectos relacionados a especialização produtiva e à desnacionalização na indústria, vinculados ao ingresso de investimento direto estrangeiro, são discutidos por Luciano G. Coutinho, A especialização regressiva: um balanço do desempenho industrial pósestabilização, in João Paulo dos Reis Velloso (Coord.) Brasil: Desafios de um País em Transformação. Rio de Janeiro: J. Olympio, 1997,p. 87-106, e por Mariano Laplane e Fernando Sarti, Novo ciclo de investimentos e espe- 
cialização produtiva, in João Paulo dos Reis Velloso (Coord.) O Brasil e o Mundo no Limiar do Novo Século, v. II. Rio de Janeiro: J. Olympio, 1998.

Sobre os efeitos da privatização na indústria, não há avaliações mais abrangentes. Entretanto, um louvável esforço nesse sentido é constituído pelos trabalhos de Marcelo Pinho e José Maria F.J. da Silveira, Privatização e Estratégias corporativas: uma análise da experiência brasileira no período 1990-1994, Nova Economia, 8 (2), dezembro de 1998, p. 109-129, e Os efeitos da privatização sobre a estrutura industrial da siderurgia brasileira, Economia e Sociedade, 10, junho de 1998, p. 81-109.

Também no plano institucional há carência de trabalhos com características de diagnóstico e avaliação geral das relações entre política (ou desenvolvimento) industrial e instituições em sentido amplo. Uma honrosa exceção é o trabalho pioneiro de Newton P. Bueno, Um modelo de histerese institucional para a análise da política industrial brasileira. Pesquisa e Planejamento Econômico, 26 (2), agosto de 1996, p. 333-348.

A chamada questão regional, do ponto de vista da distribuição geográfica da produção industrial, vem merecendo crescente atenção mormente com o acirramento da guerra fiscal. Dentre outros trabalhos importantes destaco os de Wilson Cano, Concentração e desconcentração regional no Brasil, 1970-1995. Economia e Sociedade, 8, junho de 1997; Clélio Campolina Diniz, Desenvolvimento poligonal no Brasil: nem desconcentração, nem contínua polarização. Nova Economia, 3 (1), setembro de 1993,p.35-64; Clélio Campolina Diniz e Marco A. Crocco, Reestruturação econômica e impacto regional: o novo mapa da indústria brasileira. Nova Economia, 6 (1), julho de 1996, p. 77-103, e Carlos E. G. Cavalcanti e Sérgio Prado, Aspectos da guerrafiscal no Brasil. São Paulo: FUNDAP, 1997.

Por fim, os impactos das reformas (econômicas e institucionais) sobre emprego, produtividade, relações de trabalho, distribuição de renda e pobreza são discutidos, entre outros, por: Marcio Pochmann, O trabalho e as recentes transformações econômicas no Brasil, in Carlos Anibal Nogueira da Costa e Carlos Alberto Arruda (Orgs.), Em Busca do Futuro, op. cit., cap. 9; José Márcio Camargo, Marcelo Neri e Maurício Cortez Reis, Emprego e produtividade no Brasil na década de 1990, in Renato Baumann (Org.), Brasil: uma década em transição. Ri o de Janeiro: Campus, 1999, cap.7, e Marcelo Neri e José Márcio Camargo,Efeitos distributivos das reformas estruturais no Brasil, in Baumann, op. cit., cap. 8. 